\title{
Cristina Peri Rossi lee a Clarice Lispector: Discurso introspectivo y los límites naturalizados de la "escritura femenina" *
}

\author{
Cristina Peri Rossi reads Clarice Lispector: Introspective \\ discourse and the naturalized limits of "feminine writing"
}

\author{
María Amanda Saldías Palomino \\ Universidad de Concepción. Concepción, Chile \\ masaldiasp@gmail.com
}

\section{RESUMEN}

A diferencia de lo que afirma Cristina Peri Rossi sobre la introspección en la obra de Clarice Lispector, entendiéndola como un rasgo propio de la escritura femenina, propongo que el discurso introspectivo en la obra de la escritora brasilera subvierte y supera los límites naturalizados que el discurso masculino del canon fija para la literatura producida por mujeres.

Palabras clave: Introspección, escritura femenina, canon masculino, naturalización, literatura de mujeres.

\section{ABSTRACT}

In contrast to what Cristina Peri Rossi asserts about introspection in Clarice Lispector's work, understanding it as an specific feature of the feminine writing, I propose that the introspective discourse in the work of the Brazilian writer subverts and exceeds

"Este artículo forma parte de la tesis de Doctorado en Literatura Latinoamericana (Universidad de Concepción, Chile), en desarrollo, "Ficciones de la razón moderna: conocimiento e identidades de género en La pasión según G.H., de Clarice Lispector, y La nave de los locos, de Cristina Peri Rossi”, financiada y apoyada por la Comisión Nacional de Investigación Científica y Tecnológica, CONICYT. 
the naturalized limits fixed by the canonical male discourse for the literature produced by women.

Keywords: Introspection, feminine writing, male canon, naturalization, women's literature.

Recibido: 07.11.2012. Aceptado: 02.01.2013.

A propósito de la revisión de las regulaciones de género que conforman A la lectura canónica masculina de la literatura de mujeres, la escritora mexicana Rosario Castellanos sostiene que las mujeres que adhieren a la lógica que naturaliza esa producción literaria, atendiendo a una supuesta correspondencia natural entre el género de quien escribe y el texto creado, continúan situándose en el camino de la abnegación y la subordinación (en Castillo, 2003: 334).

Desde la óptica de una crítica literaria feminista que efectivamente busque deconstruir el régimen logocéntrico en el que la producción cultural de las mujeres ha sido sistemáticamente invisibilizada mediante la naturalización del género, Butler argumenta que para esa crítica no es suficiente determinar si las mujeres están bien representadas en el lenguaje y la política, sino también liberar la propia categoría de mujeres de esas identidades ontológicas producidas por las mismas estructuras de poder de las que desean emanciparse (1992: 15-16).

De acuerdo con lo expuesto, me interesa analizar la lectura que efectúa la escritora Cristina Peri Rossi (1942-) de la obra narrativa de su par brasilera Clarice Lispector (1925-1977), donde aquélla identifica la escritura introspectiva de esta última como modelo de lo que la visión naturalizada de la literatura de mujeres ha comprendido como escritura femenina. Frente a esta lectura de Peri Rossi sobre la narrativa de Lispector, postulo que es precisamente a través de un discurso introspectivo que esta escritora logra subvertir esa lectura naturalizadora, tornando difusas las fronteras entre un discurso guiado por la intuición y otro guiado por la razón al entrelazarlos, volviendo así problemática cualquier categorización estática de su escritura.

En primera instancia, me referiré a diversas declaraciones emitidas por Peri Rossi, donde expone su percepción acerca de la obra y la figura de Clarice Lispector, para después proceder a contrastar su punto de vista con la revisión de La pasión según G.H. (1964), en conjunto con Revelación de un mundo, compilación de las crónicas publicadas por la escritora brasilera en Jornal do Brasil entre 1967 y 1973, y sus dos últimas obras narrativas, 
La hora de la estrella (1977) y Un soplo de vida. Pulsaciones (1978), donde la introspección, en tanto modalidad discursiva, propiciaría, por un lado, una reflexión metaliteraria y, por otro, un cuestionamiento a las naturalizaciones de género que permiten que los sujetos sean inteligibles como tales en el discurso logocéntrico.

\section{CRISTINA PERI ROSSI LEE A CLARICE LISPECTOR: LA NATURALIZACIÓN DE LO FEMENINO}

Leí por primera vez los relatos de Clarice Lispector hace muchos años, en Montevideo, mi ciudad natal, en la primera traducción que cayó en mis manos: Lazos de familia, publicada por Monte Ávila, Caracas. Fue una revelación. ¿Quién era esta escritora que rompía todas las convenciones del género, que declaraba: "digo lo que tengo que decir sin literatura" y huía de cualquier clasificación, rechazaba ser una "intelectual” y se negaba a conceder entrevistas? (Peri Rossi, 2001).

En este fragmento de su ensayo "Clarice Lispector o la introspección" (2001), la escritora uruguaya Cristina Peri Rossi expone, tanto a sus propios/as lectores/as como a los/las de Clarice Lispector, una relación autora/ lectora ${ }^{1}$, que es desconocida para gran parte de ellos/as ${ }^{2}$. Asimismo, en otras entrevistas y artículos, Peri Rossi reconoce a Lispector como una de sus escritoras de cabecera, considerándola responsable de la modernización de la literatura de su país al introducir "la ruptura del yo, la introspección, la sensación como forma de identidad, la duda allí donde el cuento omnisciente proponía la certeza" (2001: 171). Al igual que como Benedito Nunes (1982) y otros/as críticos/as han distinguido en las obras de Lispector, esa introspección a la que alude Peri Rossi se manifestaría en la escritura de la autora brasilera privilegiando las sensaciones por sobre los hechos, "la hondura de la mirada", mediante la cual "se buscaba a sí misma y buscándose, encontraba al otro, a la otra”, negándose a establecer un hilo conductor fijo que impidiera el flujo de esa comunicación cercana al trance místico (Peri Rossi, 2001: 170).

${ }^{1}$ Además de ser una de sus lectoras más entusiastas, Peri Rossi también traduce dos de sus libros de cuentos: Lazos de familia (1988) y Silencio (1995).

${ }^{2}$ Dado que mi lectura se efectúa desde las teorías feministas y de género, inscribo la alternativa masculina y femenina pues me parece fundamental romper con el lenguaje excluyente que invisibiliza las diferencias de género a través del uso homogeneizante del masculino. 
Esa predilección por una narrativa introspectiva en la obra de Lispector, lleva a Peri Rossi a afirmar que "su escritura solamente puede ser femenina, por el tipo de percepción que ella tiene” (Pérez Fondevilla, 2005: 187), agregando que, a diferencia de Kafka, uno de los escritores con los que habitualmente es comparada, "la literatura de Clarice Lispector es de una gran sensualidad, por tanto, femenina" (172). Por otra parte, al detenerse en esa declaración de Lispector donde ella rechaza ser identificada como intelectual, Peri Rossi la explica, especificando que aquélla "escribe con la intuición, con el instinto. Ambas -intuición e instinto- son herramientas que se han considerado tradicionalmente femeninas" (Pérez Fondevilla, 2005: 173).

Sobre esta caracterización de lo que debería ser considerado como femenino, Rosario Castellanos concuerda con Beauvoir cuando ésta reflexiona sobre las capacidades que han sido tradicionalmente designadas como "naturales" de los hombres y de las mujeres, distinción en la que reconocería la influencia del discurso filosófico clásico - un área donde la presencia de mujeres ha sido sistemáticamente invisibilizada. Al respecto, Castellanos señala que la"[a]tención, voluntad e inteligencia definen a la aproximación masculina que se apropia de su objeto de conocimiento; a las mujeres se les permiten las descontroladas respuestas 'naturales': instinto animal y los inexplicables relámpagos de la intuición” (en Castillo, 2003: 334). Ese discurso filosófico otorgaría luego las bases para lo que Guerra define como la "praxis del poder patriarcal" que ha naturalizado las diferencias entre hombres y mujeres, legitimando la subordinación de estas últimas (2008: 12) mediante esa "noción estereotípica de lo femenino, destacando aspectos tales como un estilo sutil y poético, la presentación de conflictos del corazón y el esbozo de los trazos íntimos del alma femenina”, una valoración efectuada "desde los parámetros establecidos por los hombres, pertenecientes en su gran mayoría a una élite blanca y letrada" (2008: 9).

Considerando esta crítica de Castellanos y Guerra a lo que se ha definido como "naturalmente" femenino por el discurso logocéntrico, y en adhesión a esa perspectiva crítica feminista propuesta por Butler explicada al comienzo de este trabajo, considero que el problema de la lectura de Peri Rossi no residiría entonces en determinar la introspección como rasgo fundamental de la escritura de la primera, sino específicamente en cómo la escritora uruguaya lee dicho rasgo. Como se puede percibir en sus diversas declaraciones sobre el tema, su lectura aún se mantendría dentro de esa "trampa metafísica", como la llama Moi a propósito del concepto de "metafísica de la presencia” postulado por Derrida (Moi, 1989: 124), que impediría construir una 
nueva definición menos restrictiva de lo femenino que la que ha sido repetida por el discurso canónico masculino (Franco, 1986: 35)3. Pues, como la misma Peri Rossi expone en una entrevista a Ana Nuño (1999), el carácter subjetivista e intimista de la literatura de mujeres, restringida al ámbito de lo privado, forma parte de la canonización que el discurso logocéntrico hace de esta producción no para destacarla, sino, por el contrario, para inferiorizarla, razón por lo que apela a "adjudicarnos la misma libertad o más que se han adjudicado ellos" (13).

En relación a esa libertad creativa a la que, según Peri Rossi, deben aspirar las escritoras, se advierte que Lispector exploraría en su escritura el riesgo de vaciarse de todo lo aprendido para intentar una nueva vía, no sólo para aproximarse a la acción de escribir, sino también para comprender el misterio de la existencia misma, como expresa citando a Thoreau (Lispector, 2005: 138) en "Aprendiendo a vivir", una de sus crónicas periodísticas. Según este postulado, podríamos leer su escritura introspectiva como esa búsqueda de vaciamiento, esa desroización o estado de corazón puro que alcanza temporalmente la protagonista de La pasión según G.H. cuando se desprende de toda estructura mental anterior para realmente conocer, ser y pueda hacerse presente la intuición, el instinto (Lispector, 2005: 150):

[...] en fin, qué hacer sino meditar para caer en aquel vacío pleno que sólo se alcanza con la meditación. Meditar no tiene que dar resultados: la meditación puede verse como fin de sí misma. Medito sin palabras y sobre nada. Lo que me confunde la vida es escribir (Lispector, 1989: 10).

En esta cita de la "Dedicatoria" que introduce La hora de la estrella (1989), meditar puede ser una acción que se justifica por sí misma, un "pensar para nada" (2001: 15) como dice la protagonista de La pasión según G.H, rompiendo con ese principio de finalidad que es requisito para el pensamiento racional hegemónico, de manera que la meditación se entiende como el

\footnotetext{
${ }^{3}$ Una muestra de esa lectura masculina canónica, la encontramos en la referencia que realiza Jean Franco a la introducción de la antología Novísimos narradores hispanoamericanos (1981), de Ángel Rama (donde, dicho sea de paso, éste incluye sólo a dos escritoras: Cristina Peri Rossi y Rosario Ferré), en la que el crítico uruguayo precisa que los sentimientos y no la sexualidad son el terreno propio de la escritora, para lo cual cita como ejemplo a Clarice Lispector, Armonía Sommers, Luisa Josefina Hernández y Beatriz Guido (Franco, 1986: 40).

${ }^{4}$ La cita "Sólo cuando olvidamos todos nuestros conocimientos empezamos a saber", que es la que Lispector toma de este filósofo, reformador social y naturalista estadounidense (1817-1862), pertenece al Diario de Thoreau, cuyas ideas acerca de la vinculación del ser humano con su entorno natural, la libertad y la religión guardan mucha relación con las que Lispector expone en sus obras.
} 
camino para poder alcanzar ese estado que se precisa para lidiar con la confusión que trae la escritura. "Para escribir tengo que instalarme en el vacío. Es en este vacío donde existo intuitivamente. Pero es un vacío terriblemente peligroso: de él extraigo sangre" (15), dice el narrador Autor de Un soplo de vida (1978) y, una vez instalado allí, el sujeto puede naufragar en ese estadio pre-verbal del Imaginario, como describe Benedito Nunes, del cual emergerá siendo una voz "dubitativa" "entregada al lenguaje -a los poderes y a la impotencia del lenguaje, distante y próxima a lo real, extralingüística, indecible" (Nunes, 1982: 20) .

Meditación, sin embargo, no es lo mismo que introspección. De acuerdo a la definición reseñada en el Diccionario de la Real Academia, la meditación correspondería a la "acción y efecto" de "[a]plicar con profunda atención el pensamiento a la consideración de algo, o discurrir sobre los medios de conocerlo o conseguirlo". En cambio, la introspección, derivada del verbo latino, introspicere ("mirar adentro"), se refiere a la "[o]bservación interior de los propios actos o estados de ánimo o de conciencia”. Por consiguiente, para esta autora la intuición constituiría otra forma de aprehender el mundo, no obstante esta vía carezca de validez frente a la autoridad del modelo masculino racional; la meditación, en tanto, formaría parte de ese acto introspectivo que lleva a cabo la escritura de Lispector, puesto que si en él está involucrado "con atención el pensamiento para la consideración de algo", la introspección necesita de otros elementos para alcanzar esa "observación interior", donde el sujeto pueda instalarse también en la experiencia sensual. Cuando Lispector declara no ser una intelectual por no usar lo que tradicionalmente hemos entendido por inteligencia, sino el instinto y la intuición, ella estaría, en realidad, desmarcándose de esa visión hegemónica de la actividad intelectual que privilegia el conocimiento abstracto, desincardinado 6 : "Yo también quería escribir, y serían dos o tres líneas, sobre cuando un dolor físico pasa. De cómo el cuerpo agradecido, todavía jadeando, ve hasta qué punto el alma es también el cuerpo" (2005: 161).

En contraste con ese presupuesto epistemológico dominante, Lispector postula una "sensibilidad inteligente", es decir, "una que no sólo se conmueve sino que por así decirlo piensa sin hacerlo la cabeza", a la cual ella considera un don "[y] como un don puede sofocarse por la falta de uso o

${ }^{5}$ La traducción del portugués es mía.

${ }^{6}$ Uso el término "desincardinado" siguiendo el concepto de incardinamiento empleado por Rosi Braidotti, que correspondería a una redifinición feminista de la subjetividad, vinculada esta vez a "un nuevo materialismo que desarrolla el concepto de materialidad corporal poniendo énfasis en la estructura corporizada [sic] y, por lo tanto, sexualmente diferenciada, del hablante" (2000: 29). 
perfeccionarse por el uso" (2005: 128-129). Esta sensibilidad inteligente, afincada en la experiencia material del sujeto, se apartaría de la lógica racional que se estructura en un pensamiento dicotómico, excluyente, donde el alma no puede ser el cuerpo, ni el sujeto el objeto, ni lo masculino femenino, o viceversa, sin alterar las bases epistemológicas que hacen inteligible el mundo que conocemos.

Como canal para esa otra inteligencia reconocida por Lispector, el discurso introspectivo permitiría a la autora "[p]asar del reino de la lógica a la de la evidencia viva. Perder la seguridad, para ganar la verdad" (Cixous, 2001: 171), quizá el tópico central de toda su obra: olvidar las certezas del orden logocéntrico para reconocer que lo verdadero está compuesto de contradicciones y que se halla en ese punto donde se diluyen los límites entre lo decible y lo indecible, donde pierden sentido las jerarquías entre los sujetos y se confunden las identidades: "Ese yo que son ustedes porque no aguanto ser nada más que yo, necesito de los otros para mantenerme en pie, tonto que soy, yo torcido [...]" (1989: 10).

Por otra parte, como indiqué con anterioridad, el mundo de las ideas ha sido tradicionalmente un ámbito cerrado para las mujeres, de modo que si éstas desean realmente articular nuevas formas de entender la construcción de la realidad y de los sujetos, deben practicar, sin remordimientos, lo que Adrienne Rich concibe como "deslealtad a la civilización", es decir, la desobediencia a aquellas normativas masculinas de pensamiento que, por un lado, sedimentan las identidades (Braidotti, 2000: 69) y, por otro, naturalizan las que constituyen, en realidad, fronteras ficticias entre conceptos como intuición y razón, naturaleza y cultura, cuerpo y alma, inmanencia y trascendencia. En cuanto a la narrativa de Lispector, constatamos que esas fronteras son puestas a prueba y transgredidas constantemente, de manera que la intuición y la razón no serían excluyentes entre sí ni tampoco propiedades naturales de un género sexual, conviviendo en un mismo discurso y también construyéndolo: "Hasta entonces no había tenido el valor de dejarme guiar por lo que no conozco, y rumbo a lo que desconozco: mis previsiones condicionaban de antemano lo que vería. [...] Mis previsiones me cerraban el mundo" (2001: 16).

Este proceso de reconocimiento de los propios límites discursivos y racionales que experimenta la protagonista de $L P S G H$, a medida que intenta relatar la experiencia vivida a través del lenguaje conocido, es el mismo que

${ }^{7}$ A partir de ahora, utilizaré las abreviaturas LPSGH, RDUM, LHDLE y USDV para referirme respectivamente a los textos La pasión según G.H., Revelación de un mundo, La hora de la estrella y Un soplo de vida. 
viven los narradores de las otras obras de ficción de Lispector revisadas. Ante esta constatación de lo que Benedito Nunes considera como el hallazgo final en los relatos de Lispector, el "fracaso del lenguaje" (1982: 20), dicha autora buscaría en su escritura evitar ese discurso que falla debido a sus propias reglas, las que clausuran de antemano cualquier posibilidad de explorar esos espacios del mundo de las "pulsaciones", como anuncia el subtítulo de $U S D V$, en el que las ideas están teñidas de la sensualidad de la experiencia del cuerpo:

Ángela: Sentí la pulsación de la vena en mi cuello, sentí el pulso y el latir del corazón y de repente reconocí que tenía un cuerpo. Por primera vez de la materia surgió el alma. Era la primera vez que yo era una. Una y deleitosa. Yo me poseía. El espíritu poseía el cuerpo, el cuerpo hacía palpitar el espíritu (2008: 48).

El descubrimiento de una identidad donde no se escinden el cuerpo del espíritu nos habla de una escritura que pretende, de forma similar al narrador de esta obra citada, un discurso donde "nada tuviese recortes ni definiciones: así todo se entrelazaría en un movimiento circular" (27), eludiendo a través de este procedimiento cerrarse o sedimentarse. El ejercicio "a veces doloroso" de extrañamiento que supone la introspección, pues el sujeto se contempla a sí mismo desde la ajenidad (Peri Rossi, 2001: 172), conduciría a distinguir la realidad material y la espiritual, pero no para mantenerlas separadas ni para otorgarles una valoración diferenciada, sino con el fin de demostrar que son interdependientes en este proceso de (auto)conocimiento, de la misma forma que lo son vida y escritura: "Vivir es mágico y enteramente inexplicable. Yo comprendo mejor la muerte. Ser cotidiano es un vicio. ¿Yo qué soy? Soy un pensamiento. ¿Tengo en mí el soplo? ¿Tengo? ¿Quién es ése que tiene? ¿Quién habla por mí? ¿Tengo un cuerpo y un espíritu? ¿Yo soy un yo?" $(2008: 18,19)$.

\section{DISCURSO INTROSPECTIVO Y UNA ECONOMÍA ALTERNATIVA DE PENSAMIENTO}

Como es posible observar, la introspección discursiva en la narrativa de Lispector prepararía las condiciones necesarias tanto para generar la reflexión metaficcional como para indagar en la construcción discursiva del sujeto, quien existiría a medida que se nombra y es nombrado, exponiendo la "na- 
turaleza especular del lenguaje moderno", como señala Martínez Simón en su análisis de La hora de la estrella (2007: 439), donde el yo vaciado de todo signo de identidad, anónimo, "disfraza con la escritura la máscara de su identidad” (444), hablando como otro. Es así que en esa obra Lispector se vale del narrador Rodrigo M. para contar la historia de una mujer y éste, a su vez, se vale de Macabea, el personaje que no tiene conciencia de su subjetividad, para cumplir lo que él estima, "más que una invención", una obligación (1989: 15): "En este momento quiero hablar de la norestina. Es eso: ella, como una zorra vagabunda, era teleguiada sólo por sí misma. Porque se había reducido a sí misma. También yo, de fracaso en fracaso, me reduje a mí mismo, pero por lo menos quiero encontrar el mundo y su Dios" (1989: 19).

$\mathrm{Si}$, como afirma Rosi Braidotti, "[e]s, evidentemente, la inscripción en el lenguaje que convierte al sujeto incardinado en un "yo» hablante, o sea en una entidad funcional, socializada, generizada" (Braidotti, 2004: 43), es en el discurso narrativo de los textos de Lispector donde debemos seguir las pistas que conducen hacia la desestabilización del modelo de pensamiento que ha naturalizado la construcción de las identidades: "Poseo a medida que designo; y éste es el esplendor de tener un lenguaje. Pero poseo mucho más en la medida que no consigo designar" (2001: 154).

Pero el lenguaje disponible, como reflejo de la crisis de sentido que se experimenta (Gálvez-Breton, 1990: 64), también demuestra estar en crisis: "Lo que aquí está escrito, mío o de Ángela, son restos de una demolición del alma, son cortes laterales de una realidad que se me escapa continuamente. Esos fragmentos de libro quieren decir que yo trabajo entre ruinas" (20), confiesa el narrador de $U S D V$, quien, al querer dar cuenta de este sistema que colapsa, descubre que las palabras han desaparecido porque los significados se han agotado y "[n] os comunicamos como sordomudos con las manos" (2008: 14).

A pesar del colapso discursivo en el que se sustenta esta narración introspectiva, al estar hecha de ruinas, esta condición precaria significa paradójicamente una oportunidad para abandonar en el texto la posición de poder que asume tradicionalmente el hablante del lenguaje logocéntrico, que tanto en $L H D L E$ como en $U S D V$ está representado en la figura del narrador masculino. Para Gálvez-Breton es justamente "la apropiación de esta voz narrativa masculina [...] el primer paso hacia la desautorización del lenguaje masculino"8 (1990: 62), la estrategia que posibilita la derogación

${ }^{8}$ La traducción es mía. 
de las asimetrías que lo conforman, generando el desplazamiento constante de los roles tanto del sujeto y como del objeto del discurso:

( $\mathrm{Si}$ estoy demorando un poco en hacer que ocurra lo que ya preveo vagamente, lo hago porque necesito tomar varias fotos de esa alagoana. También porque, si hubiese algún lector para esta historia, quiero que se embeba de la joven así como un paño encharcado. La muchacha es una verdad de la que yo no quería saber. No sé a quién acusar, pero ha de haber un reo) (Lispector, 1989: 38-39).

Rodrigo M., narrador de $L H D L E$, asume el deber de contar la historia de la migrante alagoana, Macabea, desde su posición de sujeto privilegiado, porque la muchacha "tiene derecho al grito", pero indicando, al mismo tiempo, que ella "era callada (porque no tenía nada qué decir)" (33). Sin embargo, como constata Renata Kroll, Lispector se rehúsa a practicar en su escritura el "dar masculino" designado por Cixous, el "yo te doy una voz y tú hablarás mi lengua", que sería otra forma de colonización, de apropiación del otro (Kroll, 2004: 18) y Macabea se escabulle constantemente del código lingüístico logocéntrico, porque su realidad "no encaja en ningún sistema, ninguna lengua, ningún orden $y$, de este modo, Macabea queda en cierta manera detrás del texto" (Kroll, 2004: 19). La presencia de la muchacha invade la narración de Rodrigo M., a pesar del deseo suyo de ajustarse al "Orden" y no "caer en el abismo poblado de gritos: el Infierno de la libertad" (36), circunstancia que lo lleva, en cambio, a articular un relato lleno de retrocesos y contradicciones, que se reconoce conquistado por esa otra posibilidad de subjetividad que representa Macabea.

Esta alteridad subjetiva de Macabea también se manifestaría en el hecho de que ella no acostumbra pensar voluntariamente, porque puede "verse privada de sî" (32), ya que pensar conlleva el peligro de darse cuenta de la situación en que vive y quizá si su vida es algo que disfruta mucho, puede ser castigada por eso y "dejar de ser": "¿Tendría la sensación de que vivía para nada? No puedo saberlo, pero creo que no. Sólo una vez se hizo una pregunta trágica: ¿quién soy yo? Se asustó tanto que dejó de pensar por completo" (32). Por otra parte, pensar en su propia condición de sujeto, tener un momento de soledad para sí misma es algo que Macabea considera un lujo, del cual sólo puede disfrutar por primera vez cuando pide permiso para faltar al trabajo y se queda sola en el cuarto que comparte con otras cuatro chicas: "Encontrarse consigo misma era un bien que hasta entonces no había conocido. Creo que nunca estuve tan contenta en esta vida, pensó. No 
debía nada a nadie y nadie le debía nada. Hasta se dio el lujo de aburrirse: un aburrimiento bien distinto" (41).

Este "aburrimiento" que menciona Rodrigo M. en su narración es lo que se conoce como ocio, circunstancia especial que permite que tenga lugar la introspección, "bien" al cual tienen acceso los narradores de las tres obras narrativas revisadas, privilegio que nos habla de la aguda percepción de Lispector sobre la situación social del intelectual y el artista en la sociedad en la que se desenvuelve. Al respecto, tanto en LPSGH como en LHDLE y $U S D V$, los narradores se presentan a sí mismos como artistas -aficionada la de la primera; fracasados, los de las otras dos obras-, de clase social acomodada, posición económica que les permite disponer de tiempo libre para realizar las actividades que deseen, no las que deben cumplir para obtener el sustento; además, son cultos y su relación con la obra de arte y sus objetos ha sido de distancia, nunca de compromiso total:

Todo eso me ha dado el leve tono de preclímax de quien sabe que, auscultando los objetos, algo de los mismos saldrá que le será dado y, a su vez, devuelto a los objetos. Tal vez haya sido ese tono de preclímax lo que veía yo en la sonriente fotografía torva de un rostro cuya palabra es un silencio inexpresivo, todos los retratos de personas son un retrato de Mona Lisa (2001: 25).

Como escultora aficionada, G.H. está habituada al trabajo con un material del cual extraerá el objeto artístico ahí latente, pero ese objeto no forma ni formará parte de ella, de su intimidad, hecho que da a su existencia ese tono de "pre-clímax" asegurado por esa noción que ella vislumbra como "la objetividad forzada de luchar con aquello que no era yo" (25). El discurso introspectivo, tanto de G.H. como de Rodrigo M. y del Autor, se enunciará en un comienzo desde esta situación existencial, la del pre-clímax, que es la del sujeto que se ajusta a las normativas sociales, culturales y lingüísticas del sistema logocéntrico, cuyas subjetividades e identidades han sido definidas externamente: "A mi alrededor extiendo la tranquilidad que procede de llegar a un grado de realización hasta el punto de ser G.H., incluso en las maletas. También para mi denominada vida interior he asumido, sin sentir, mi reputación: me trato como las personas me tratan, soy aquellos que los demás ven de mí" (2001: 24). Luego, la condición discursiva privilegiada desde la que narran estos tres personajes, por su posición social, ha implicado asumir una subjetividad previa, como las iniciales de las maletas de G.H., vivida tibiamente, porque les ha sido adjudicada por otros, en 
tanto la introspección podría ser leída como la búsqueda de ese yo indefinido, contradictorio, en continua construcción que desconocen: "(Veo que he procurado dar a Macabea una situación mía: yo necesito de unas horas diarias de soledad, porque si no, «me muero»)" (1989: 65).

En contraste, Macabea y Ángela Pralini, las figuras femeninas, existen en el clímax existencial que no precisa justificación ni sentido: "Civilizar mi vida es expulsarme de mí. Civilizar mi existencia más profunda sería expulsar mi naturaleza. Todo ello, no obstante, no habla de mi posible significado. [...] Estoy perdida: no tengo hábitos" (2008: 65). Por ese motivo, cuando Macabea y Ángela Pralini aparecen en el relato, desarman el proyecto narrativo inicial de los sujetos privilegiados, forzándolos a mirarse a sí mismos desde la alteridad que introducen discursiva y existencialmente, al igual como lo hace la cucaracha con G.H., experiencia ante la cual la aproximación racional prueba no ser la única válida, entrando en el juego la intuición de la "sensibilidad inteligente" sugerida por Lispector: "Sentía ella en sí misma algo equivalente a lo que mi mirada veía en ella? ¿Hasta qué punto se aprovechaba de sí misma y de lo que era? Al menos de algún modo indirecto, ¿sabía que caminaba arrastrándose? ¿O arrastrarse es algo que la gente misma no sabe que está haciendo?” (2001: 80, 81).

Aunque tanto en $L H D L E$ como en USDV, el personaje femenino es objetualizado en un principio, dado que es la contraparte que requiere el proyecto narrativo del sujeto masculino -Macabea, objeto narrado; Ángela, quien a su vez escribe su nacimiento, vida y muerte para que su creador pueda entender la suya-, a medida que éste articula su narración, comprueba que él también es una "creación" y sufre la melancolía de esta condición, pues desearía haber permanecido en la "inmanencia sagrada de la Nada" (27), ese espacio donde se ubica el Creador absoluto, saturado de poder, pero también libre de binarismos. Renata Kroll vincula este desplazamiento del sujeto masculino de esa posición convencional de poder que ocupa en el lenguaje logocéntrico con el concepto de écriture féminine en économie libidineuse de Cixous e Irigaray", que consistiría en "dejar a los otros en su alteridad y nulidad". Luego, como sucede en $L H D L E$, tanto la autora como

\footnotetext{
${ }^{9}$ Realizando una relectura de Freud, Cixous distingue dos economías libidinales, una masculina, basada en la apropiación y una femenina, sustentada en el gasto y el goce; ante estas dos definiciones, la autora afirma que sólo se podrá subvertir este sistema de oposiciones si estas categorías son parte de un constante cuestionamiento, que evite la esencialización de las diferencias (2001: 173). Por su parte, Irigaray apela a una mímesis feminista para salir de la economía del logos, mediante la que se repita-interprete "el modo en que al interior del discurso queda determinado lo femenino" (2009: 58), desbordando los límites de representación que el lenguaje masculino fija de la mujer y la hace perderse en la "mascarada de la feminidad" (2009: 62).
} 
el narrador y la protagonista "quedan sin excepción como figuras marginales, entre los cuales se difuminan las fronteras [...]” (Kroll, 2004: 19), confundiéndose entre sí, sin que ninguno prevalezca sobre el otro, revirtiéndose esa jerarquización entre creador/a-creatura que articula la escritura de la economía masculina.

La narración en estas obras ya no se trataría solamente entonces del sujeto que escribe ni del sujeto que narra ni del que es narrado, sino de subvertir toda una economía de pensamiento que rige el sistema discursivo convencional, donde contar hechos externos responde a una finalidad de ganancia. Por el contrario, el discurso narrativo de la introspección formaría parte de lo que Cixous entiende como educación libidinal: ir a la raíz del proceso creador, ese momento en que la identidad no está determinada por categorías fijas, sino que lo que prima es el deseo (de decir, de saber, de ser), o mejor aún, cuando se deshace la identidad construida por categorías externas, atribuidas por ese sistema lingüístico de la economía de la apropiación: "Y tampoco yo tengo nombre, y éste es mi nombre. $Y$ porque me despersonalizo al punto de no tener nombre, respondo cada vez que alguien dice: yo" (2001: 153).

En consecuencia, el discurso introspectivo en la narrativa de Lispector no correspondería al modelo de escritura femenina fijado por el discurso masculino, en el que la literatura escrita por mujeres es entendida en un sentido representacional, buscando una "identidad-esencia" de la mujer (Richard, 1993: 34), sino a la inscripción de una economía discursiva diferente, "que desvía la linealidad de un proyecto, mina el objeto-meta de un deseo, hace que estalle la polarización sobre un único goce, desconcierta la fidelidad a un único discurso..." (Irigaray, 2009: 21). Dicha inscripción es posible gracias a lo que Nelly Richard llama "disidencia de identidad", una práctica escritural que se configura como herramienta para "descontrolar la pauta de la discursividad masculina/hegemónica, [compartiendo] el 'devenir/minoritario' (Deleuze-Guattari) de un femenino que opera como paradigma de desterritorialización de los regímenes de poder y captura de la identidad normada y centrada por la cultura oficial" (Richard, 1993: 36). Siguiendo la noción de feminidad que propone Kristeva como "aquello que margina el sistema simbólico machista” (en Moi, 1988: 173) ${ }^{10}$, para Richard

\footnotetext{
${ }^{10}$ Kristeva argumenta desde su idea del lenguaje como "un complejo proceso lingüístico, más que un sistema monolítico", y desde su reflexión sobre los postulados psicoanalíticos del Orden Simbólico lacaniano y el chora platónico, que la "concepción de la diferencia como elemento binario encerrado o capturado entre los dos polos opuestos de lo masculino y lo femenino nos impide ver todo lo que escape a esta rígida estructuración" (en Moi, 1988: 162). Asimismo, el acto de dar
} 
la práctica de la disidencia de identidad no sería exclusiva de la literatura escrita por mujeres, dado que ese "devenir femenino" ya no estaría prefijado por lo biológico y su carga de normatividad, sino que constituiría un modo subversivo de enunciar el mundo, rebasando los límites naturalizadores del discurso logocéntrico.

Aunque entiendo que en este contexto el concepto de devenir minoritario femenino que Richard toma de Deleuze y Guattari se aplica a la escritura como práctica subversiva, no lo comparto totalmente cuando es llevado sin ser problematizado al plano de la construcción de las identidades de género, básicamente porque desde que nacemos -incluso desde antes de nuestro nacimiento, como bien demuestra Adrienne Rich en su ensayo "Políticas de localización" (1986) ${ }^{11}$ - se nos asigna y no "devenimos" libremente un género. No obstante, me parece que reformular el concepto de escritura femenina, desligándola de lo biológico y lo esencialista, apuntando a esa subversión y desborde de los límites de la economía logocéntrica, puede significar un método de aproximación mucho más productivo que el de la lectura naturalizada que aún predomina en el canon estético masculino cuando aborda la producción literaria de la escritora.

"Pensar es un acto. Sentir es un hecho. Los dos juntos son yo que escribo lo que estoy escribiendo" (1989: 13): para concluir, el discurso introspectivo en la narrativa de Clarice Lispector conduce a sus lectores/as a cuestionar los márgenes fijados por la lectura canónica masculina para la producción literaria de mujeres, mediante el uso transgresor del lenguaje para enunciar esa "observación interior" o introspección, derribando las dicotomías de la economía patriarcal, incluso si el resultado de este desafío expone una derrota. A diferencia de Peri Rossi, quien no ve una "voluntad de rebeldía" en el discurso introspectivo de Lispector, a pesar de que, tal como ella misma destaca, ésta "pone en tela de juicio el universo entero de creencias patriarcales, recibidas, el orden heredado" (2001: 173), considero que el mismo sentido que la escritora brasilera da a la introspección en su escritura constituye ya un signo de desacato, quizá menos violento que el que se presenta en la obra

nombres y clasificar sería para ella no sólo un acto de poder, sino que expresaría "el deseo de regular y organizar la realidad mediante categorías bien definidas" (en Moi, 1988: 168) marginando aquellas subjetividades e identidades que perturben esa voluntad de orden.

${ }^{11}$ En este ensayo, Rich emplea el concepto "políticas de localización" para referirse al género como parte de un discurso político regulatorio donde los sujetos, aun antes de nacer, ya están categorizados según el sexo anatómico, el color de su piel y la clase social que vayan a poseer, signos que establecerán una localización en el mundo, la cual para esta autora debe ser reapropiada políticamente para desde allí subvertir las normativas de dominación y exclusión que articulan el sistema patriarcal. 
de otras autoras, pero no por eso menos efectivo.

Finalmente, concuerdo con Eliana Ortega cuando postula que "una de las funciones primordiales de la crítica feminista sería exacerbar las diferencias, mirar de cerca las ambigüedades, los conflictos, las paradojas entre nosotros/as" (1996: 22), tarea que sólo se puede realizar practicando "una crítica de las instituciones y, antes que nada, del sistema literario en sí mismo" (Franco, 1986: 32), el cual, como hemos podido advertir en la lectura de Peri Rossi sobre la escritura de Lispector, aún precisa de muchas revisiones y reformulaciones, en especial cuando enfrenta obras que se apartan de los preceptos impuestos por la lectura masculina canónica.

\section{REFERENCIAS}

Braidotti, Rosi. (2000). Sujetos nómades: Corporización y diferencia sexual en la teoría feminista contemporánea. Buenos Aires: Paidós.

. (2004). Sobre el sujeto feminista femenino o desde el "sí mismomujer" hasta el "otro mujer". En Fischer, Amalia (ed.), Feminismo, diferencia sexual y subjetividad nómade (pp. 33-54). Barcelona: Gedisa.

Butler, Judith. (1992). Contingent foundations: Feminism and the question of 'postmodernism'. En Judith Butler y Joan W. Scott (eds.), Feminists theorize the political (pp. 3-21). Nueva York \& Londres: Routledge.

Castillo, Debra. (2003). Finding feminisms. En Sara Castro-Klarén (ed.), Narrativa femenina en América Latina. Prácticas y perspectivas teóricas/Latin American women's narrative. Practices and theoretical perspectives (pp. 351-375). Madrid: Iberoamericana y Vervuert.

Cixous, Hélène. (2001) [1995]. La risa de la medusa: Ensayos sobre la escritura. Barcelona: Anthropos.

Franco, Jean. (1986). Apuntes sobre la crítica feminista y la literatura hispanoamericana. Hispamérica, 15, 45, 31-43.

Gálvez-Breton, Mara. (1990). Post-feminist discourse in Clarice Lispector's The hour of the star". En Lucía Guerra (ed.), Splintering darkness: Latin American writers in search of themselves (pp. 63-78). Pittsburgh, P.A.: Latin American Review Press.

Guerra, Lucía. (2008). Mujer y escritura: fundamentos teóricos de la crítica feminista. Santiago: Cuarto Propio.

Irigaray, Luce. (2009) [1977]. Ese sexo que no es uno. Madrid: Akal.

Kroll, Renata. (2004). Recuperación del yo por pérdida del sentido: sobre el principio estético en Clarice Lispector. Revista de Letras, 44, 2, 13-29. 
Lispector, Clarice. (1989) [1977]. La hora de la estrella. Madrid: Siruela. . (2001) [1964]. La pasión según G.H. Barcelona: Muchnik Editores.

. (2005) [1984]. Revelación de un mundo. Buenos Aires: Adriana Hidalgo Editora.

. (2008) [1978]. Un soplo de vida (Pulsaciones). Madrid: Siruela.

Martínez Simón, José María. (2007). La reflexividad como experiencia moderna del lenguaje: Cervantes y Clarice Lispector. En Matías Barchino Pérez (coord.), Territorios de la Mancha: Versiones y subversiones cervantinas en la literatura hispanoamericana. Actas del VI Congreso Internacional de la Asociación Española de Estudios Literarios Hispanoamericanos (pp.437-446). Cuenca: Ediciones Universidad de Castilla-La Mancha.

Moi, Toril. (1988). Teoría literaria feminista. Madrid: Cátedra.

. (1989). Feminist, female, feminine. En Catherine Belsey y Jane Moore (eds.), The feminist reader: Essays in gender and the politics of literary criticism (pp. 117-132). Nueva York: Basil Blackwell.

Nunes, Benedito. (1982). Clarice Lispector ou o naufragio da introspeção. Colóquio/Letras, 70, 13-22.

Nuño, Ana. (1999). Entrevista a Cristina Peri Rossi. Quimera, 185, 9-12.

Ortega, Eliana. (1996). Lo que se hereda no se hurta: ensayos de crítica literaria feminista. Santiago: Cuarto Propio.

Pérez Fondevilla, Aina. (2005). Del deseo y sus accesos: una entrevista a Cristina Peri Rossi. Lectora, 11, 181-193.

Peri Rossi, Cristina. (2001). Clarice Lispector o la introspección. Turia, 58, 170-174.

Rich, Adrienne. (1986). A politics of location. [On line] Disponible en http://www.medmedia.it/review/numero2/en/art3.htm.

Richard, Nelly. (1993). Masculino/Femenino: prácticas de la diferencia y cultura democrática. Santiago: Francisco Zegers Editor. 